\title{
API-monitoring of synthetic pyrethroids by gas chromatography with mass spectrometric detection
}

\author{
(C) Aisylu Z. Mukharlyamova, ${ }^{*+}$ Igor M. Fitsev, Elvira R. Rakhmetova, \\ Aygul G. Mukhammetshina, Alsy R. Makaeva, \\ Oksana V. Shlyamina, and Zhanna R. Nasybullina \\ Federal Center for Toxicological, Radiation and Biological Safety (FSBSI «FCTRBS-RRVI»). \\ Nauchny Gorodok-2. Kazan.420075. Republic of Tatarstan.Russia.E-mail: fitzev@mail.ru
}

\begin{abstract}
*Supervising author; ${ }^{+}$Corresponding author
Keywords: synthetic pyrethroids, insecticides, fungicides, acaricides, gas chromatography, mass spectrometry, honey bees, API-monitoring.
\end{abstract}

\begin{abstract}
The article presents the results of API (Latin Ápis - bee) monitoring the content of residual amounts of synthetic pyrethroids in honey bees using gas chromatography with mass spectrometric detection (GC-MS).

The pesticides discussed in this article were selected based on the results of API monitoring of honey bees using GC / MS. The proposed GC-MS method for monitoring synthetic pyrethroids makes it possible not only to identify the causes of lethal intoxication of bees, but also to prevent the possible consequences of synthetic pyrethroids getting into beekeeping products and, consequently, their distribution along trophic routes. The latter has a direct impact on the quality of human life safety.

It has been shown that for the detection by GC-MS of synthetic pyrethroids contained in a bee matrix, an important role is played by correctly selected conditions for sample preparation and purification of the extract, which contribute to the isolation of the target compounds from a complex matrix, which are present in it, often at the level of the minimum permissible level (MDU). In this work, sample preparation was carried out by solid-phase extraction (SPE) on a chromatographic column using a C18 sorbent with grafted octadecyl groups. A GC-MS multimethod has been developed for the determination of synthetic pyrethroids (prometrine, bifenthrin, $\beta$ cyagalotrin, isomers of permethrin and cypermethrin, fenvalerate, deltamethrin, which, along with other insecticides, for example, neonicotinoids, are frequent causes of lethal intoxication of bees.

Quantitative determination of synthetic pyrethroids under GC-MS conditions is carried out in the registration mode of selective ions (main and confirmatory ions, respectively). The proposed method for the determination of synthetic pyrethroids for the purposes of their API monitoring is characterized by a detection limit that does not exceed the MRL in ecomonitoring objects.
\end{abstract}

\section{References}

[1] I.M. Fitsev, O.V. Shlyamina, A.R. Makaeva, G.R. Nasybullina, A.M. Saifutdinov. Detection of Cypermethrin Residues in Toxicological Control Objects using Gas Chromatography - Mass Spectrometry with Solid-Phase Extraction. Int. J. of Mechanical and Production Engineering Research and Development. 2020. Vol.10. No.3. P.5563-5570.

[2] S.S. Albaseer, R.N. Rao, Y.V. Swamy, K. Mukkanti. An overview of sample preparation and extraction of synthetic pyrethroids from water, sediment andsoil. J. Chromatogr. A. 2010. Vol.1217. P.5537-5554.

[3] I.M. Fitsev, O.V. Shlyamina, A.Z. Mukharlyamova, S.L. Mokhtarova, E.R. Rakhmetova, A.G. Mukhammetshina, and Zh.R. Nasybullina. Gas chromatography-mass spectrometry screening persistent organic pollutant in environmental monitoring of vital activity objects. Butlerov Communications. 2020. Vol.62. No.6. P.89-99. DOI: 10.37952/ROI-jbc-01/20-62-6-89

[4] M. Saitta, G.Di. Bella, M.R. Fede, Turco V. Lo, A.G. Potorti, R. Rando, M.T. Russo, G. Dugo. Gas chromatography-tandem mass spectrometry multi-residual analysis of contaminants in Italian honey samples. Food Addit. Contam. PartA: Chem. Anal. Control Expo. Risk Assess. 2017. P.1-9.

[5] T. Schettgen, P. Dewes, T. Kraus. A method for the simultaneous quantification of eight metabolites of synthetic pyrethroids in urine of the general population using gas chromatography-tandem mass spectrometry. Anal.Bioanal. Chem. 2016. Vol.408. P.5467-5478. 
API-MONITORING OF SYNTHETIC PYRETHROIDS BY GAS CHROMATOGRAPHY WITH MASS...

[6] A.R. Makaeva, O.V. Shlyamina, and I.M. Fitsev. Monitoring the nutritional value and chemical safety of the main feeds of the Republic of Tatarstan according to the results of studies carried out in 2019. Butlerov Communications. 2020. Vol.62. No.4. P.123-128. DOI: 10.37952/ROI-jbc-01/20-62-4-123

[7] I.M. Fitsev, O.V. Shlyamina, A.M. Sayfutdinov, A.R. Makaeva. Quechers sample preparation for the determination of pesticides by chromatomass spectrometry. Collection of materials of the International conference "Fundamental scientific research as a factor of ensuring the competitiveness of society and the state". April 10, 2020. Belgorod, Russia.

[8] L. Carrasco-Letelier, Y. Mendoza-Spina, M.B. Branchiccela. Acute contact toxicity test of insecticides (Cipermetrina 25, Lorsban 48E, Thionex 35) on honeybees in the southwestern zone of Uruguay. Chemosphere. 2012. Vol.88. P.439-444.

[9] P. Mineau, K.M. Harding, M. Whiteside, M.R. Fletcher, D. Garthwaite, L.D. Knopper. Using reports of bee mortality in the field to calibrate laboratory-derived pesticide risk indices. Environ.Entomol. 2008. Vol.37. P.546-554.

[10] B.E. Richter, B.A. Jones, J.L. Ezzell, N.L. Porter, N. Avdalovic, C. Pohl. Accelerated Solvent Extraction: A Technique for Sample Preparation. Anal. Chem. 1996. Vol.68. P.1033-1039.

[11] A. Dallegrave, T.M. Pizzolato, F. Barreto, E. Eljarrat, D. Barcelo. Methodology for trace analysis of 17 pyrethroids and chlorpyrifos in foodstuff by gas chromatography-tandem mass spectrometry. Anal. Bioanal. Chem. 2016. Vol.408. P.7689-7697.

[12] Y.B. Li, R.A. Kelley, T.D. Anderson, M.J. Lydy. Development and comparison of two multi-residue methods for the analysis of select pesticides in honey bees, pollen, and wax by gas chromatographyquadrupole mass spectrometry. Talanta. 2015. Vol.140. P.81-87.

[13] M. Fernandez, Y. Pico, J. Manes. Analytical methods for pesticide residue determination in bee products. J. Food Prot. 2002. Vol.65. P.1502-1511.

[14] E.M. Kristenson, S. Shahmiri, C.J. Slooten, R.J.J. Vreuls, U.A.Th. Brinkman. Matrix Solid-Phase Dispersion Micro-Extraction of Pesticides from Single Insects with Subsequent GC-MS Analysis. Chromatographia. 2004. Vol.59. P.315-320.

[15] GOST R 8.736-2011 State system for ensuring the uniformity of measurements (GSI). Direct multiple measurements. Methods for processing measurement results. The main provisions. Moscow: Standartinform. 2013. (russian)

[16] GOST 34100.1-2017 / ISO / IEC Guide 98-1: 2009. The uncertainty of the measurement. Introduction to the guide to the expression of uncertainty in measurement. Moscow: Standartinform. 2018. (russian)

[17] Determination of pesticide residues in food, agricultural raw materials, and environmental objects. Collection of guidelines. MUK 4.1.2162-4.1.2176-07 4.1. Methods of control. Chemical factor. [Electronic resource]. URL: http://docs.cntd.ru/document/1200079314 (accessed 15.08.2020).

[18] P. Calatayud-Vernich, F. Calatayud, E. Simó, Y. Picó. Efficiency of QuEChERS approach for determining 52 pesticide residues in honey and honeybees. Methods X. 2016. Vol.3. P.452-458.

[19] L. Marconi, S. Ghini, R. Colombo, A.G. Sabatini, S. Girottic. Determination of organophosphorus pesticides in honeybees after solid-phase microextraction. J. Chromatogr.A. 2001. Vol.922. P.257-265.

[20] N.A. Pilling, P.C. Jepson. Synergism between EBI fungicides and a pyrethroid insecticide in the honey bee (Apis meliffera). Pest.Sci. 1993. Vol.39. P.293-297. 